\title{
Assessment of Hurdles Faced by Women Entrepreneurs in Livestock Sector during Covid 19 Lockdown
}

\author{
A. Indhu Prathibha*, V. Bhanu Rekha, .V. J. Ajay kumar, \\ M. Nithya Quintoil and V. Sowmiya
}

${ }^{1}$ Department of Veterinary Public Health \& Epidemiology, RIVER, Rajiv Gandhi Institute of Veterinary Education \& Research, Puducherry, India

*Corresponding author

Keywords

Woman entrepreneurs,

Livestock,

Telephonicinterview, Covid-19 lockdown, Hurdles

\section{Article Info}

Accepted:

22 June 2020

Available Online:

10 July 2020

\begin{abstract}
A B S T R A C T
Entrepreneurship in livestock sector is more beneficial for women in rural areas as it enables them to add to the family income. The present study was done to ascertain the hurdles faced by women livestock entrepreneurs during Covid-19 lockdown. Livestock women entrepreneurs comprising 25 dairy farmers and 25 goat farmers in Puducherry and adjoining areas of Tamil Nadu were interviewed over telephone using a pre-structured interview schedule pertaining to the conditions before and during lockdown. Results of our study have clearly pointed out that there was a change in availability of animals for purchase and sale, Change in feeding practices and Sale of milk before and during lockdown period. Further Dairy farmers were satisfied to some extent as they had a regular income through sale of milk, but the goat farmers were not satisfied as their source of revenue was severely affected during Covid-19 Lockdown. In spite of the reduced income during Covid-19 crisis, the respondents expressed a greater satisfaction because of family participation in the business. To conclude Covid-19 imposed a negative impact on the economic status of the women entrepreneurs in livestock by reducing their income drastically.
\end{abstract}

\section{Introduction}

Entrepreneurs are instrumental in initiating and sustaining socio economic development in developing nations. In India, Women play a pivotal transformative role in animal husbandry growth in spite of persistent obstacles and economic constraints faced by them in animal husbandry. In recent times Government of India has given due importance to women empowerment in the country and several schemes have been introduced for the upliftment of women entrepreneurs who can contribute towards improvement of their socio economic conditions and the growth of economy of the country (Mishra et al., 2017).

In rural India, Dairy farming and Goat rearing are the two important enterprises which are easily adopted and followed by woman to meet out their economic needs and nutritional 
requirements of their families. Increasing demand for milk and milk products in recent years has intensified dairy farming as a profitable enterprise for rural woman (Mishra et al., 2017). Goat rearing is an important enterprise not only for livelihood of weaker section of society but it also helps in meeting nutritional requirement of farm families (Gopala et al., 2010).

The recent pandemic of Covid-19 immensely affected the economy of various sectors in India and throughout the world with huge implications on agriculture and livestock sector in developing nations like India. Considering the above points in mind, the present study was designed to envisage the hurdles faced by woman Entrepreneurs in Livestock Sector during this Covid-19 lockdown and to elucidate the impact on women farming enterprise.

\section{Materials and Methods}

A total of 50 woman livestock entrepreneurs which included 25 dairy farmers and 25 goat farmers were selected by convenient sampling during the second lockdown. Across section altelephonic survey was conducted in Puducherry and adjoining areas of Tamil Nadu using a pre structured interview schedule during the first week of May. An interview schedule consisting of 14 questions (9 closed and 5 open) pertaining to conditions before and after lockdown was prepared in consultation with subject matter specialists after reviewing the literature.

Data collected from the respondents over telephone included viz., education, income, experience in livestock entrepreneurship and household size. The responses from the farmers were coded and analyzed. The problems faced by the entrepreneurs before and during Covid-19 lockdown was compared using mean score values.

\section{Results and Discussion}

\section{Demographic profile of the respondents}

The demographic details of the 50 entrepreneurs illustrate (Table 1) majority of respondents were between 36-50 years of age group and 27 per cent of our respondents were illiterate.

\section{Availability of animals for purchase and sale}

Seventy four per cent of the entrepreneurs reported that animals are available for purchase, 4 per cent reported that animals are not available for purchase and 22 per cent reported that they have not purchased animals as it has been passed onto them by their families. The procurement of cows inside and outside Puducherry was 44 and 32 per cent respectively.

\section{Change in feeding practices}

Among 25 dairy farmers, 23 per cent stall fed their animals, 30 per cent allowed for grazing and 47 per cent followed both stall feeding and grazing before lockdown. During lockdown this has drastically changed causing 53 per cent respondents to adopt stall feeding (Fig.1). It was also reported that they were mixing urea with straw to feed the animals.

All the dairy entrepreneurs (100 per cent) reported that they could not meet the feeding requirement of their animals due to increased feed cost during lockdown especially the price of concentrates had increased by 350 rupees per bag of $25 \mathrm{Kg}$ (Fig.2).

The availability of feed and fodders were found to be 100 per cent before lockdown whereas during lockdown this has reduced to 86 per cent (Fig.3). 


\section{Sale of milk}

The dairy entrepreneurs stated that sale of milk before lockdown occurred by milk cooperative society (33.33per cent), through milkman delivering at door - step to the consumers (43.33 per cent) and by both (23.33 per cent). But during lockdown the sale of milk to the co-operative society had increased to 66.67 per cent whereas the sale to consumers directly had decreased to 13.33 per cent and only 20 per cent sold to both cooperative society and consumers (Fig.4).

Around 70 per cent of the goat holders sold their goats to butchers through middleman and before lockdown all the goat holders sold their goats to the butchers. But during lockdown sale of goats to butchers had drastically reduced to 13.33 per cent (Fig.5)

Out of the total respondents, 73.33 per cent entrepreneurs used personal transportation for the sale of products and for other errands like feed purchase; hospital etc. whereas remaining 26.67 per cent reported that they used public transport. During lockdown goat holders were mostly affected due to nonavailability of transportation and middleman as well.

As a preventive measure for Covid-19, 80 per cent of the respondents reported that they sprinkle mixture of neem and turmeric water around animal shelters twice a day.

Table.1 Demographic profile of the respondents

\begin{tabular}{|c|c|c|}
\hline Category & Particulars & Percentage (\%) \\
\hline \multirow{3}{*}{ Age (years) } & $20-35$ & 27 \\
\cline { 2 - 3 } & $36-50$ & 50 \\
\hline \multirow{2}{*}{ Education } & more than 50 & 23 \\
\hline \multirow{3}{*}{ Household size (No.) } & School & 53 \\
\cline { 2 - 3 } & Graduate & 20 \\
\hline & Illiterate & 27 \\
\cline { 2 - 3 } & $2-5$ & 83 \\
\hline
\end{tabular}

Fig.1 Feeding practices followed by the entrepreneurs

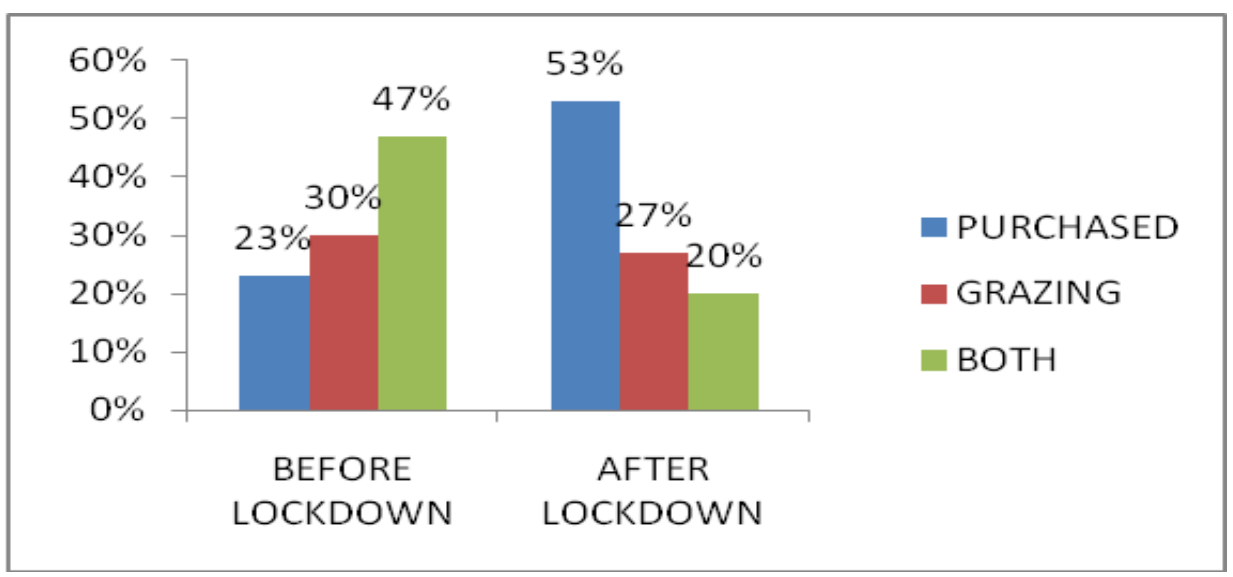


Fig.2 Price of Concentrates

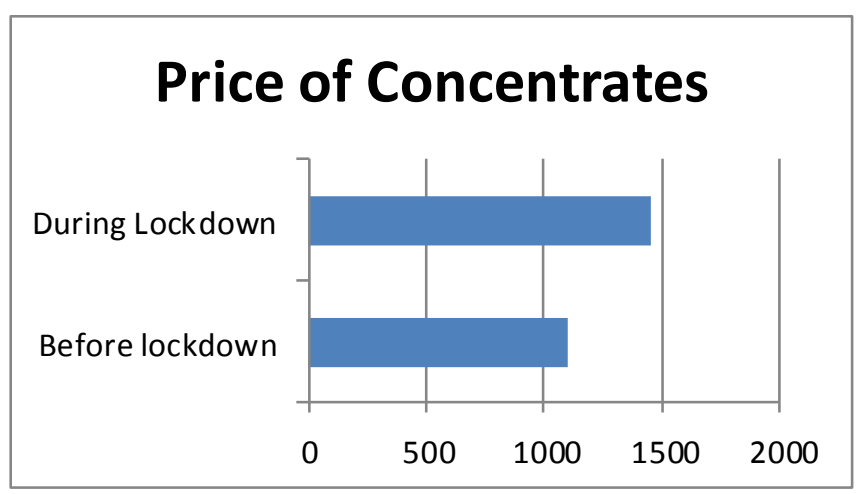

Fig.3 Availability of feed and fodder

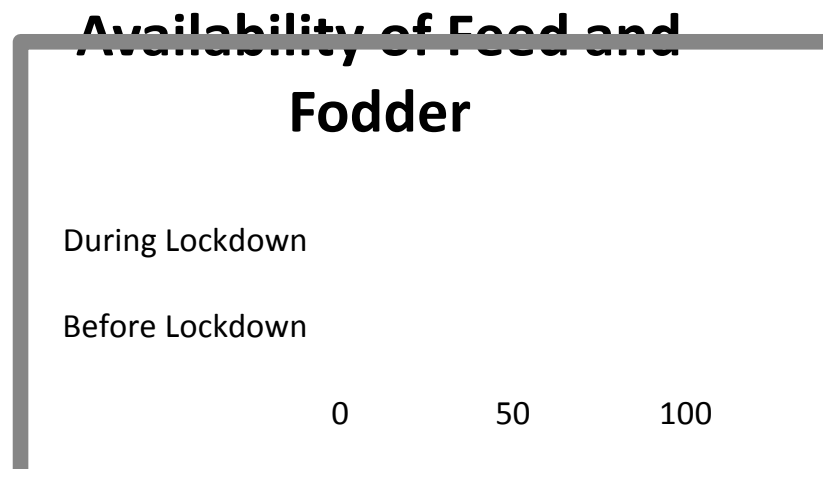

Fig.4 Sale of milk before and during lockdown

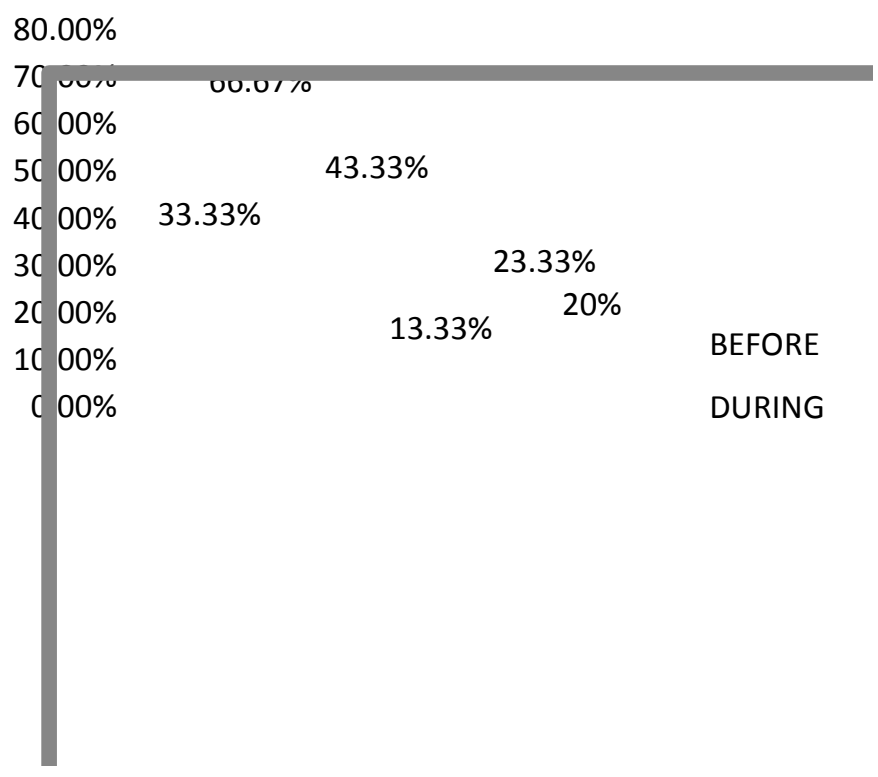


Fig.5 Sale of goats before and during lockdown

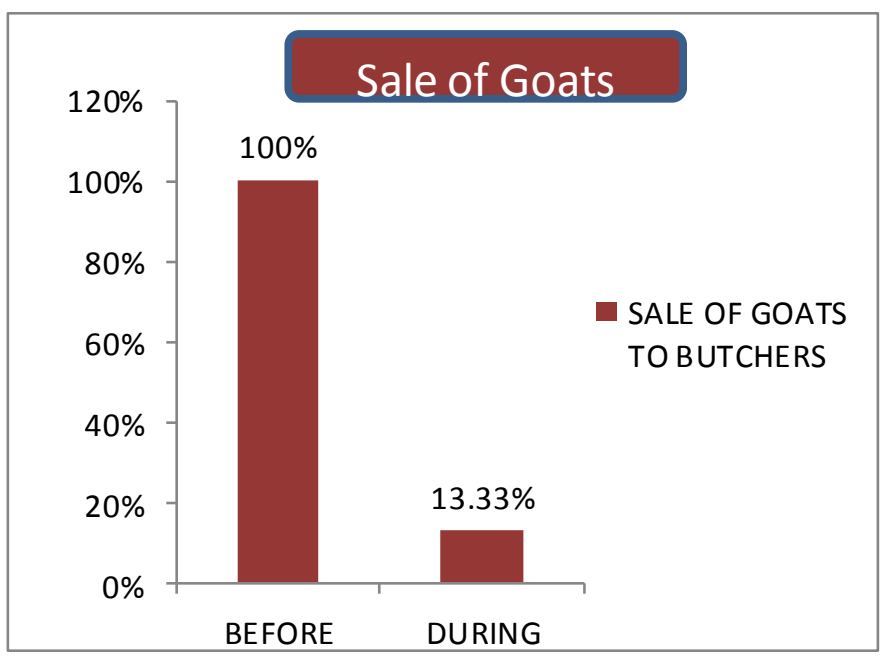

Fig.6 Hurdles faced by the entrepreneurs during lockdown

$\begin{array}{lll}13.33 \% & 13.33 \% & \text { SECURITY CHECKUP } \\ & & \text { HIGH FEED COST } \\ 23.33 \% & & \text { TRANSPORTATION } \\ & & \text { OTHERS } \\ & & \end{array}$

Fig.7 Family participation in the business before and after lockdown

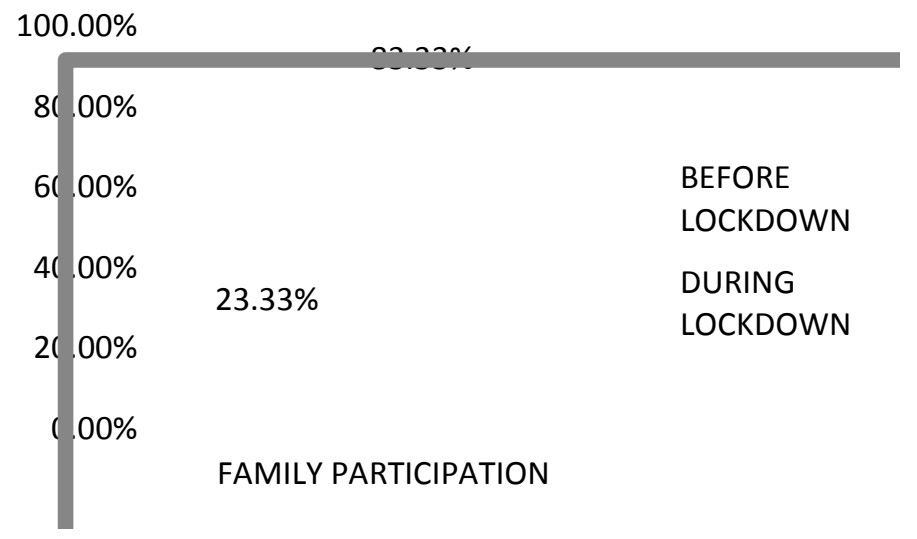


All the goat holders reported that there was no market during lockdown for sale of goats thus leading to economic loss among the goat holders.

Availability of feed and fodder decreased which was predominantly due to lack of labour and market.

All the dairy entrepreneurs they are facing financial problems due to non-availability of middleman and transportation.

Due to lockdown the monthly income of the entrepreneurs had decreased considerably, which was mainly due to non-availability of proper channel for marketing, high feed cost and reduced product prices etc. Out of 50 farmers studied, 90 per cent of the entrepreneurs experienced reduced income during lockdown of which 50 per cent were goat holders.

The availability of veterinary services was also decreased from 100 per cent to 90 per cent due to Covid-19 pandemic. Bara and Ganguly (2016) also reported the lack of veterinary services after cyclone Phailin in Odisha. In the present study 90 per cent of the entrepreneurs expressed their dissatisfaction due to reduced income during this Covid-19 lockdown period.

The study revealed the hurdles faced by the entrepreneurs during lockdown were Covid19 associated security checkup(13.33 per cent), high feed cost (50 per cent; all are dairy holders), transportation (23.33 per cent) and other factors (13.33 per cent) including nonavailability of veterinary care, reduced milk price, lack of market etc. (Fig.6) This is in line with the results of Manimekalai and Bharathy (2013), who reported that the major constraints faced by dairy entrepreneurs were high cost of concentrate (96.67 per cent), lack of availability of veterinary services in the village (79.67 per cent), non-remunerative price for milk (100 per cent),problem of poor irrigation facilities for growing fodder crops for the livestock animals (62.50 per cent).

In conclusion lockdown associated social distancing and self-quarantine helps to prevent the communal spread of Covid-19 but also caused a negative impact on the economic status of the entrepreneurs in livestock by reducing their income. In spite of the reduced income during Covid-19 crisis, the respondents expressed a greater satisfaction because of family participation in the business. Dairy farmers were satisfied partially as they had a regular income through sale of milk, but the goat farmers were not satisfied as their livelihood was severely affected during covid19 Lockdown.

\section{References}

Bara, S.P.S., and Ganguli, D.2016. Effect of Natural Disaster on Livestock Farmers: The case of Cyclone 'Phailin'in Odisha. International Conference on Agriculture, Food Science, Natural Resource Management and Environmental Dynamics: The Technology, People and Sustainable Development. ISBN-978-93-85822-285.

Gopala, G.T., Veeranna, K.C., and Shivakumar K. Radder. 2010. Research Journal of Animal Husbandry and Dairy Science. 1(2):80-82.

Manimekalai, P., and Bharathy, R.S. 2013. A study on Satisfaction level of women entrepreneurs in Dairy Sector in Salem District of Tamil Nadu. Asia Pacific Journal of Research. 1(4): 43-53.

Mishra, S, Kunwar, $\mathrm{N}$ and Tripathi, S. 2017.Involvement of women in dairy enterprise and used modern technologies and training needs in dairy farming. International Journal of Home Science. 3(3): 234-237. 


\section{How to cite this article:}

Indhu Prathibha, A., V. Bhanu Rekha, V. J. Ajay Kumar, M. Nithya Quintoil and Sowmiya, V. 2020. Assessment of Hurdles Faced by Women Entrepreneurs in Livestock Sector during Covid 19 Lockdown. Int.J.Curr.Microbiol.App.Sci. 9(07): 3033-3039.

doi: https://doi.org/10.20546/ijcmas.2020.907.357 